\title{
The dynamic implications of tourism and environmental quality
}

DOI:

10.1111/jpet.12330

\section{Document Version}

Accepted author manuscript

Link to publication record in Manchester Research Explorer

\section{Citation for published version (APA):}

Ouattara, B., Perez-Barahona, A., \& Strobl, E. (2018). The dynamic implications of tourism and environmental quality. Journal of Public Economic Theory. https://doi.org/10.1111/jpet.12330

\section{Published in:}

Journal of Public Economic Theory

\section{Citing this paper}

Please note that where the full-text provided on Manchester Research Explorer is the Author Accepted Manuscript or Proof version this may differ from the final Published version. If citing, it is advised that you check and use the publisher's definitive version.

\section{General rights}

Copyright and moral rights for the publications made accessible in the Research Explorer are retained by the authors and/or other copyright owners and it is a condition of accessing publications that users recognise and abide by the legal requirements associated with these rights.

\section{Takedown policy}

If you believe that this document breaches copyright please refer to the University of Manchester's Takedown Procedures [http://man.ac.uk/04Y6Bo] or contact uml.scholarlycommunications@manchester.ac.uk providing relevant details, so we can investigate your claim.

\section{OPEN ACCESS}




\title{
The dynamic implications of tourism and environmental quality*
}

\author{
Bazoumana Ouattara \\ University of Manchester (UK) \\ Agustín Pérez-Barahona \\ THEMA, Université de Cergy-Pontoise and Ecole Polytechnique (France) \\ Eric Strobl \\ University of Bern and IPAG (France) $)^{\dagger}$
}

July 18, 2018

\begin{abstract}
Many studies draw attention to the rising number of tourists seeking destinations in environmental hotspots. However, it is also recognized that tourism activities significantly deteriorate the environment. Our paper investigates the dynamic interaction between tourism and environmental quality, focusing on its effect on the development of tourism-driven economies. We use a theoretical model in order to study the dynamic implications of this interaction. In this respect, we point out the role played by environmental maintenance activities and ecotourism. Ecotourism allows the economy to improve welfare in the long-term, but we identify a social cost in terms of current generations' welfare. Finally, the existence of imbalance effects between tourism infrastructures and environmental quality provides new insights about the transitional dynamics of tourism destinations.
\end{abstract}

${ }^{*}$ We are thankful to Robert Elliott and Pierre-Alain Jayet for their comments. We would also like to express our gratitude to the conference participants at ASSET 2017, Algers (Algelia), 48th Annual Monetary Studies Conference, CCMF, Nassau (The Bahamas), and SALISES 2016, Bridgetown (Barbados), for useful discussion. The Associate Editor of this Journal and two anonymous referees provided suggestions that helped to make substantial improvements to the paper. Agustín Pérez-Barahona acknowledges financial support from the Chaire Développement Durable (Ecole Polytechnique - EDF) and the Labex MME-DII.

${ }^{\dagger}$ Corresponding author at: Department of Economics and Oeschger Centre for Climate Change Research, University of Bern, Switzerland; e-mail: eastrobl13@gmail.com. 
Keywords: Tourism, Environmental quality, Economic dynamics.

Journal of Economic Literature: O44, Q56, R11. 


\section{Introduction}

Numerous studies point out that environmental quality plays a fundamental role in attracting tourists for many economies; see, amongst others, Font (2000); and Christ et al. (2003). However visitors, and the corresponding provision of tourist services, frequently cause significant environmental degradation (May, 1995; Gossling et al., 2002; and Burak et al., 2004). Thus intensively promoting tourism may in turn reduce the future attractiveness of destinations located in environmental hotspots. Indeed it has long been recognized that there may be reciprocal causality between tourism and environmental quality (for instance, McConnell and Duff, 1976; McConnell, 1977; Tisdell, 2001; Huybers and Bennett, 2003; or Gopalakrishnan et al., 2011). The aim of this paper is to explicitly study the relationship between tourism and environmental quality. In particular, since this interaction can influence the development of tourism-driven economies, we pay attention to its dynamic implications.

A handful of theoretical papers have already studied the dynamic properties of the reciprocal causality of tourism and environmental quality, focusing on the sustainability of tourism activities. For example, Kort et al. (2002) introduce a theoretical model to analyze the investment decisions of a tourism planner. They find that this reciprocal causality has important dynamic implications for the evolution of the environmental conditions of the economy, tourism and the subsequent investment in physical capital ("tourism infrastructures" in their paper). This framework considers a planner that maximises the (discounted stream) of touristic revenues. However, they do not study the social optimum where a policy maker would also take into account households' preferences. Moreover, pollution abatement activities are not explicitly included as a decision variable for the planner. Closer to the neoclassical growth theory, papers such as Gómez et al. (2008), Lozano et al. (2008) or Rey-Maquieira et al. (2009) take into account households' welfare, together with the possibility of physical capital investments, in a problem of tourism quality where overcrowding directly reduces (i.e., not only through environmental degradation) the attractiveness of the destination. They identify significant long-run effects of the interaction between tourism and environmental quality in a decentralized economy. Nevertheless, apart from the stability property of the long-run equilibrium (saddle-path), their evaluation of the short-run dynamics is mainly numerical. They do not further explore analytical properties of the dynamical transition, such as the speed convergence or the possibility of imbalance effects between physical capital and environmental quality. Furthermore, they do not study the role played by environmental maintenance activities. Based on this approach, Marsiglio (2015) incorporates pollution abatement into a social planner problem. As in the previous literature, the paper concentrates on the long-run behaviour of the economy. According to this model the long-run equilibrium (balanced 
growth path) is locally unstable and, consequently, the economy would be in the longrun at any point in time. Therefore, this set-up leaves no room to study the dynamical transition.

In this paper we provide a theoretical framework to study the dynamic implications of the reciprocal causality between tourism and environmental quality. We focus on the social optimum, including explicitly investment decisions regarding physical capital and environmental maintenance activities. To do so we consider a Ramsey-type model for tourism and environmental quality. Since the aim of our paper is to underline the dynamic dimension of the interaction between tourism and environmental quality, we provide a highly stylized framework that represents an economy where tourism is the main economic activity. Tourism services are produced by means of using labour, physical capital, and environmental quality. But, at the same time, tourism activities induce environmental degradation, which will undermine the future provision of tourism and, thus, income and welfare. We neglect additional features of tourism, such as the distinction between quantity and quality of tourism or the diversification of the economic activity, in order to tease out the main dynamical mechanisms of the problem, including both the long-term and the short-run response of the economy.

We show that, if the efficiency of pollution abatement is high enough, appropriate planning of tourism can sustain positive long-run levels of environmental quality, income and welfare. In the context of our set-up, and consistently with the United Nations World Tourism Organization (UNWTO, 2002), we define ecotourism as a type of tourism that involves activities with low environmental impact, paying particular attention to the environmental quality of the destination. We find that promoting ecotourism reinforces the result above. In contrast to the previous literature, we provide further analytical results regarding the short-run dynamics of the economy. Ecotourism allows the economy to improve welfare in the long-term. However, along the transition, the development of the economy will be slower (i.e., lower speed of convergence) due to the greater importance that ecotourists give to the environmental conditions of the destination. This outcome allows us to identify a social cost of ecotourism in terms of current generations' welfare. We finally note the presence of an imbalance effect between physical capital and environmental quality in tourism-driven economies. We show that developing economies, frequently endowed with substantial environmental quality but lacking of physical capital such as infrastructures or tourism facilities, optimally sacrifice part of the environmental characteristics at the beginning of their development. Therefore, the environment temporarily deteriorates due to the initial focus on the accumulation of physical capital. However, once the economy has recovered a proper balance between physical capital and environmental quality, the environmental conditions will improve because the economy 
also invests in environmental maintenance. This outcome can be linked to numerous papers finding empirical evidence of this transitional phase (among others, McElroy and Albuquerque, 1998; Silva et al., 2008; Santana-Jiménez and Hernández, 2011; and Silva and Ferreira, 2013). This result clearly depicts the emergence of an environmental Kuznet curve (EKC) (for instance, Tahvonen and Salo, 2001; Kijima et al., 2010; or Brock and Taylor, 2010), which is driven in our paper by the dynamic interaction between tourism and the environmental quality.

The paper is organized as follows. Section 2 reviews the empirical literature on the evidence of the reciprocal causality between tourism and environmental quality. With this interaction in hand, we present in Section 3 the theoretical model together with the corresponding optimal conditions. Section 4 considers the long-run behaviour of the economy, while Section 5 and 6 describe the transitional dynamics. Finally, Section 7 concludes.

\section{Review of the empirical evidence}

Importantly all of the related theoretical literature just cited assumes that there is reciprocal causality (simultaneity) between tourism and environmental quality, i.e., greater environmental quality will attract more tourists, while at the same time more tourists will lower environmental quality. In this paper we similarly assume this to be true, and thus it is constructive to review the empirical evidence in this regard. To this end we will focus on coastal tourism, since this is where much of the empirical analysis has been undertaken, and because it arguably serves as a particularly relevant case of the dual interaction between tourism and environmental quality. One may want to note that as of date there is no study explicitly testing the existence of reciprocal causality between these two aspects, but rather there are studies that have examined and provide evidence of one or the other. We here outline a representative selection of each strand of literature.

There are a considerable number of papers that show that tourists can have a detrimental effect on local environmental quality. For instance, Kocasoy (1995) shows that in the tourist resort of Cesme (Turkey) beach population density is significantly correlated with microbial pollution of the seawater across nine selected beaches. Focusing on solid waste pollution on the beach sand, Silva et al. (2008) similarly investigated how pollution was related to beach population density. More specifically, the authors counted the number of plastic cups, drinking straws, coconut shells, pamphlets, and beverage containers across transects of Boa Viagem Beach (Brazil) and related this to the number of people within the transect, and found there to be a significant positive correlation. In a study of two protected coastal dune systems Vallés et al. (2011) calculated out a dune vulner- 
ability index based, amongst other things, on the geomorphological conditions, marine influences, aeolian influence, and vegetation condition. Their findings show that dune vulnerability was related to beach access as well to the influx of visitors.

Even more evidence exists in terms of how a fall in environmental quality can affect tourism. Most of these, however, infer the impact on tourism via capturing how lower environmental quality translates into how tourists' willingness to pay or feeling of comfort. Interestingly, the impact seems to be heterogeneous across the different types of users. For instance, Brau (2008) conducted a survey of tourists in Sardinia (Italy) and, using an empirical choice model revealed the existence of strong negative effects due to the congestion of tourist attractions and the transformation of coastal environments, where this result was lower for tourists residing in 4 and 5 star accommodation facilities. Examining beaches along Costa de Caparica (Portugal), Silva and Ferreira (2013) discovered a feeling of discomfort particularly among surfers due to overcrowding. Results from a survey of beach users at Costa Brava (Spain) by Roca et al. (2009), additionally suggest that there may be differences between loyal and local users and short stay visitors. More specifically, the former were more concerned with natural beach values and environmental degradation, while the latter valued more the provision of facilities and did not feel disturbed by overcrowding. Using contingent valuation methods Beharry-Borg and Scarpa (2010) demonstrate that in the Caribbean island of Tobago beach water quality was important for tourists, and particularly so for snorkelers. Finally, in the only study that measures the impact of environmental quality on tourist numbers directly, Santana-Jimenez and Hernandez (2011) construct a time varying data set of German and United Kingdom tourists to five Canary islands and find that higher local population density discourages German tourists, but has no effect on their British counterparts.

\section{Dynamic implications}

As pointed out in the introduction, several research and policy studies recommend to take into account the dynamic interaction between tourism and environmental quality. This literature considers that this relationship is particularly important to analyze the sustainability of economic activity in tourism-driven regions. Following this view, we will investigate the dynamic implications of the reciprocal causality. We introduce in this respect a Ramsey-type model of a tourism-driven economy. In this section we present the model and the corresponding optimal conditions. We will study the long-term equilibrium and the short-run dynamics in the remaining parts of the paper.

We assume that labour and physical capital are inputs to provide tourism services. Consistently with the empirical evidence, let us introduce the reciprocal causality between 
tourism and environmental quality. We consider, on the one hand, that the environmental quality of the economy is an additional input for tourism services since tourists are also attracted by this feature of the destination. On the other hand, tourism activities will entail environmental degradation, which will compromise the future provision of tourism services. We set two main simplifications in order to highlight the dynamic interaction between tourism and environmental quality. First, we assume that tourism is the major source of income of the economy. We actually focus on the extreme case where the destination cannot diversify the economic activity. This scenario is not far from the situation of many tourism-driven economies, where tourism often is the only sector with comparative advantage. Second, since in this paper we do not explicitly study the choice between quantity and quality of tourism, tourism services will be identified as tourism arrivals in our model 1

We consider that tourism is a composite good in accordance with the tourism economics literature (for instance, McConnell, 1977; Fleischer and Rivlin, 2008; and ReyMaquieira et al., 2009). In our simplified set-up the income provided by tourism services is

$$
T(t)=F(E(t), L(t), K(t))
$$

Tourism income $T(t)$ are obtained by means of combining labour $L(t)$, physical capital $K(t)$ and environmental quality of the destination $E(t)$. Since the main source of revenue of our economy is tourism, we simply identify income $Y(t)$ as tourism services, i.e., $Y(t)=T(t)$. We will consider a Cobb-Douglas technology in order to obtain closed-form solutions:

$$
F(E(t), L(t), K(t))=A E(t)^{\alpha} L(t)^{\beta} K(t)^{\gamma},
$$

where $\alpha, \beta, \gamma>0$ are the corresponding output elasticities with $\alpha+\beta+\gamma=1$, and $A>0$ is the scale parameter ${ }^{2}$ As generally assumed in the economic growth literature, labour demand $L(t)$ equals population size $N(t)$, which is assumed to increase at an exogenous rate $n \geq 0$ with a given initial population $N(0)>0$.

Similar to Mariani et al. (2010), the evolution of the environmental quality of the economy is described as

$$
\dot{E}(t)=\sigma M(t)-\epsilon E(t)-\vartheta T(t) .
$$

Tourism has a negative impact on the environmental characteristics of the destination, while investing in maintenance $M(t)$ improves the environmental conditions. Parameters

\footnotetext{
${ }^{1}$ For further discussion about quantity vs. quality of tourism see, amongst others, Cower and Tabarrok (1995), Caserta and Russo (2002) and Fleischer and Rivlin (2008).

${ }^{2}$ Based on Rosen (1974)'s hedonic pricing theory, Rey-Maquieira et al. (2009) provide an alternative justification of this type of production function for tourism-driven economies.
} 
$\sigma, \vartheta>0$ represent, respectively, the effect of these two factors on the evolution of the environmental quality. We interprete environment quality as the environmental services required for the provision of tourism activities. Therefore, some environmental maintenance is necesary to preserve the economic value of the environment as a production factor. As in Mariani et al. (2010), the parameter $\epsilon \in(0,1)$ stands for an exogenous rate of deterioration of the environment. A typical example of this phenomenon is the erosion of beaches due to exogenous elements to our model, such as ocean currents, wave action, storms, sea levels, etc. (see for instance, Munk and Traylor, 1947). Indeed, this type of "natural" deterioration, together with the erosive impact of tourism facilities and housing, has frequently justified the implementation of beach preservation policies, such as sand replenishment of beaches, commonly known as "beach nourishment" (among others, Landry and Weeler, 2003; and Gopalakrishnan et al., 2011). In our simplified set-up, we additionally assume that there is no natural regeneration of the environment (i.e., $\epsilon \geq 0$ ). We will focus on this limit case because our aim is to underline the negative effect of tourism on the environmental conditions. If our economy was able to guarantee positive long-term levels of environmental quality, income, and welfare, adding the possibility of natural regeneration would eventually reinforce this sustainability outcome $3^{3}$

Regarding to the dynamics of the physical capital, we consider the usual law of motion

$$
\dot{K}(t)=I(t)-\delta K(t)
$$

where $I(t)$ is the investment and $\delta \in(0,1)$ represents the physical capital depreciation. As in Rey Maquiera et al. (2009) we assume for simplicity that there is no international factor mobility. Finally, the resources constraint of the economy is stated as

$$
Y(t)=C(t)+I(t)+M(t)
$$

In this paper we will focus on the social optimum. We therefore consider that the policy maker maximizes the lifetime discounted utility of the households of our economy with the temporal discount $e^{-\rho t}$, where $\rho>n$ :

$$
\max _{\{c, m\}} \int_{0}^{\infty} u(c(t)) e^{-(\rho-n) t} d t
$$

subject to

$$
\left\{\begin{array}{l}
\dot{k}(t)=f(e(t), k(t))-m(t)-c(t)-(\delta+n) k(t), \\
\dot{e}(t)=\sigma m(t)-(\epsilon+n) e(t)-\vartheta f(e(t), k(t)), \\
e(0), k(0)>0 \text { given. }
\end{array}\right.
$$

Note that all variables of the social optimum problem (6)-(7) are expressed in per-capita terms, using henceforth lowercase letters to denote this. As is customary in the tourism

\footnotetext{
${ }^{3}$ We provide comments about the case $\epsilon<0$ in the Concluding remarks.
} 
economics literature, we assume that tourism services target foreign visitors in tourismdriven economies. This is a reasonable simplification for many destinations. A representative example is the Caribbean. According to WTTC (2017a), in the Caribbean foreign visitors spending generated $72 \%$ of the direct contribution of tourism to GDP in 2016 compared with $28.0 \%$ for domestic visitors. These figures contrast with global figures, where domestic visitors generated $71.8 \%$ of the direct contribution to GDP and foreign visitors $28.2 \%$ (WTTC, 2017b). Consequently, we assume that the instantaneous utility of the resident households $u(\cdot)$ only depends on consumption $c(t)$. 4 The set of constraints (7) is obtained by using equations (1) and (5) in (3) and (4), and then rewriting the corresponding laws of motion in per-capita units. For the Cobb-Douglas technology (2), the output per capita would be $f(e(t), k(t))=A e(t)^{\alpha} k(t)^{\gamma} !^{5}$

The Hamiltonian of the social optimum problem takes the form

$$
\begin{aligned}
& H(c, m, e, k, \mu, \lambda)=u(c(t))+\mu(t)[\sigma m(t)-(\epsilon+n) e(t)-\vartheta f(e(t), k(t))] \\
& +\lambda(t)[f(e(t), k(t))-m(t)-c(t)-(\delta+n) k(t)]
\end{aligned}
$$

where $\mu(t)$ and $\lambda(t)$ are, respectively, the shadow price (co-state variable) of the environmental quality and the physical capital. Taking the corresponding first order conditions (FOC) $\partial H / \partial c(t)=0, \partial H / \partial m(t)=0, \partial H / \partial e(t)=-\dot{\mu}(t)+(\rho-n) \mu(t)$, and $\partial H / \partial k(t)=-\dot{\lambda}(t)+(\rho-n) \lambda(t)$, we state the following proposition:

Proposition 1. Every solution of the problem (6)-(7) verifies

$$
\begin{gathered}
\frac{\dot{c}(t)}{c(t)}=\frac{1}{\xi(c(t))}\left[\frac{(\sigma-\vartheta)}{\sigma} f_{k}^{\prime}-(\delta+\rho)\right], \\
\dot{k}(t)=f(e(t), k(t))-m(t)-c(t)-(\delta+n) k(t), \\
\dot{e}(t)=\sigma m(t)-(\epsilon+n) e(t)-\vartheta f(e(t), k(t)), \\
g(e(t), k(t))=0,
\end{gathered}
$$

and the transversality conditions $(T C)$

$$
\lim _{t \rightarrow \infty} e(t) \exp \left(-\int_{0}^{t}\left[(\sigma-\vartheta) f_{e}^{\prime}-\epsilon-n\right] d s\right)=0
$$

\footnotetext{
${ }^{4}$ Numerous papers in environmental economics (e.g., Dasgupta and Heal, 1974; Stiglitz, 1974; Rosendahl (1997); Geldrop and Withagen (1999); or Smulders et al., 2012) assume that natural resources only have value as a production input. Therefore, they do not directly enter agents' instantaneous utility. Following this literature we assume, in the context of our paper, that environmental quality affects social welfare only through the provision of tourism services. For the implications of including environmental conditions in the utility function see, for instance, Bosi and Desmarchelier (2017).

${ }^{5}$ For a general production function $f(e(t), k(t))$, we consider the usual neoclassical assumptions of diminishing returns, i.e., $f_{i}^{\prime}>0$ and $f_{i i}^{\prime \prime}<0$, together with $\lim _{i \rightarrow \infty} f_{i}^{\prime}=0$ and $\lim _{i \rightarrow 0} f_{i}^{\prime}=\infty$, for $i=\{e, k\}$.
} 


$$
\lim _{t \rightarrow \infty} k(t) \exp \left(-\int_{0}^{t}\left[(\sigma-\vartheta) f_{e}^{\prime}-\epsilon-n\right] d s\right)=0,
$$

where $g(e(t), k(t)) \equiv(\sigma-\vartheta) f_{e}^{\prime}-\frac{\sigma-\vartheta}{\sigma} f_{k}^{\prime}-(\epsilon-\delta), \xi(c(t)) \equiv-\frac{u^{\prime \prime}(c(t)) c(t)}{u^{\prime}(c(t)}$, and $e(0), k(0)>0$ are given.

\section{Proof. See Appendix A.}

Equation (9) is the Euler condition of the problem, which describes the trade-off between current and future consumption. In this expression $\frac{1}{\xi(c(t))}$ represents the elasticity of intertemporal substitution. In particular, $\xi(c(t))=1$ for a logarithmic utility $u(c(t))=$ $\ln c(t)$, while it is equal to a strictly positive constant $\theta \neq 1$ for $u(c(t))=\frac{c(t)^{1-\theta}-1}{1-\theta}$. Equations (10) and (11) are the law of motion of our state variables, i.e., environmental quality and physical capital. Equation (12) establishes an important relationship between the environmental conditions and the stock of physical capital of the economy at every moment of time. We will show in Section 5 that this equation has a unique solution, allowing us to express $k(t)$ as a function of the environmental quality for every $t \geq 0$, i.e., $k(t)=h(e(t))$. Hence, this property will reduce the dimension of the dynamical system, simplifying the tractability of the dynamics of the economy. Moreover, since the initial conditions for the environmental quality and the stock of physical capital are given, there may be the case that $k(0) \neq h(e(0))$. This will allow us to identify a possible imbalance effect between the environmental conditions and the endowment of physical capital of the economy. We investigate this possibility in Section 6. The last two expressions (13) and (14) are the transversality conditions associated with each state variable of our problem. Notice finally that the conditions in Proposition 1 are not only necessary but also sufficient. Following Seiertad and Sydsaeter (1987), and Le Kama and Schubert (2007), it is easy to prove that the maximized Hamiltonian is strictly concave for the Cobb-Douglas technology (2), provided that the negative impact of tourism on the environmental conditions of the economy is relatively small with respect to the efficiency of maintenance:

Proposition 2. For $\vartheta<\sigma$, the necessary conditions (9)-(14) are also sufficient.

\section{Long-run behaviour}

Let us first study the steady-state of the economy, which is defined as an equilibrium path in which all variables of the problem (6)-(7) are constant for all $t$. As in the standard neoclassical growth model without technical progress, this is a concept of long-term equilibrium that is useful to understand the main mechanisms behind the interaction between tourism and environmental quality. In particular, it allows us to illustrate the possibility of sustaining a socially optimal level of tourism activities, where the environmental quality plays a significant role in the provision of this sort of services. The 
main difficulty in this respect comes from the fact that tourism itself deteriorates the environmental conditions of the economy. This would deter in turn the future appealing of the destination and, thus, the main source of economic activity. In this section we characterize the steady-state, leaving for Section 5 and 6 the analysis of the dynamics of the economy around this equilibrium.

Consider the dynamical system (9)-(12) at the steady-state. Given the technology (2), we can establish a proposition that characterizes the long-run behaviour of our economy:

Proposition 3. For $\vartheta<\sigma$, the economy has a unique steady-state $\left(e^{*}, k^{*}, m^{*}, c^{*}\right)>0$, which is given by

$$
\begin{gathered}
e^{*}=\left(\frac{A \alpha^{1-\gamma} \gamma^{\gamma}}{\Psi_{1}^{1-\gamma} \Psi_{2}^{\gamma}}\right)^{\frac{1}{1-\gamma-\alpha}}, \\
k^{*}=\frac{\Psi_{1}}{\Psi_{2}} \frac{\gamma}{\alpha} e^{*}, \\
m^{*}=\frac{1}{\sigma}\left[\vartheta f\left(e^{*}, k^{*}\right)+(n+\epsilon) e^{*}\right], \\
c^{*}=f\left(e^{*}, k^{*}\right)-m^{*}-(\delta+n) k^{*},
\end{gathered}
$$

where $\Psi_{1} \equiv \frac{\epsilon+\rho}{\sigma-\vartheta}, \Psi_{2} \equiv \frac{\sigma}{\sigma-\vartheta}(\delta+\rho)$, and $f\left(e^{*}, k^{*}\right)=A e^{* \alpha} k^{* \gamma}$.

Proof. See Appendix B,

The proposition states that the economy can sustain a long-term economic activity, maintaining the compatibility between tourism and environmental quality. It is necessary, though, that the efficiency of the environmental maintenance $(\sigma)$ is relatively high with respect to the negative impact of tourism on the environmental conditions of the economy $(\vartheta)$. Indeed, one can verify too that the steady-state values $e^{*}, k^{*}, y^{*}$ and $c^{*}$ rise when the negative impact of tourism falls. In our model lowering the parameter $\vartheta$ can be associated with situations where a destination promotes tourism activities with a reduced environmental impact. This can be the case of ecotourism.

Ecotourism typically involves activities with low environmental impact. This effect is captured in our model by a reduction of the parameter $\vartheta$. Indeed, one can conclude from the results above that promoting ecotourism allows the economy to sustain a greater level of physical capital, environmental quality, income, and tourism activity, together with higher consumption and, thus, long-run welfare. Nevertheless, consistently with UNWTO (2002), ecotourism includes an additional dimension: "ecotourists" also give greater importance to the environmental conditions of the destination. This feature is represented in our model by a greater $\alpha$ (see Equation 2). Let us study the effect this second dimension of ecotourism on the long-run levels of the economy. Considering the characterization of the steady-state in Proposition 3 , it is possible to demonstrate that 
ecotourism also increases the long-term level of environmental quality because of this second dimension. More specifically, $\partial e^{*} / \partial \alpha>0$ for a big enough $\alpha$ (details of the proof are provided in Appendix C). Therefore, the greater importance that ecotourism gives to the environmental conditions (a larger $\alpha$ ) reinforces the effect of its reduced environmental impact (a lower $\vartheta$ ). The resulting long-run environmental quality will be even larger. However, we find that this is possible if the destination focuses on the provision of tourism services with large enough environmental content $(\alpha>\bar{\alpha}$ in Appendix C). If this is the case we can also show that the effect on $k^{*}$ is reinforced too, together with the reaction of the long-run levels of income and tourism activity (i.e., $\partial k^{*} / \partial \alpha>0$ and $\left.\partial y^{*} / \partial \alpha>0\right)$. Regarding to the long-term consumption $c^{*}$, if we additionally require that the negative impact of tourism on environmental quality is low enough, the effect of $\vartheta$ on $c^{*}$ will be reinforced as well. Thus $c^{*}$ would be even greater, leading to higher welfare in the long-term. We can summarize this outcome in the following proposition:

Proposition 4. If the economy focuses on sufficiently environmental-friendly tourism (i.e., $\alpha>\bar{\alpha}$ and $\vartheta<\bar{\vartheta}$ ) the equilibrium levels $e^{*}, k^{*}, y^{*}$ and $c^{*}$ will be higher, resulting in greater long-term welfare.

\section{Proof. See Appendix C.}

In addition to the steady-state levels, Proposition 3 also identifies the existence of an optimal proportion of production factors in the economy. Equation (16) reveals that there is a long-term ratio between physical capital and environmental quality: $k^{*} / e^{*}=$

$\frac{\Psi_{1}}{\Psi_{2}} \frac{\gamma}{\alpha}$. As we will show in the next section, there is also a fixed relationship between $e(t)$ and $k(t)$ that holds along the transition path and eventually converges to this ratio. This result highlights that a policy maker should ensure an appropriate provision of infrastructures and tourism facilities (represented in our model by the stock physical capital) that is compatible with the evolution of the environmental conditions. From a policy perspective, this outcome provides a general advise for tourism-driven economies where tourism is closely linked with the natural environment. The existence of an optimal proportion of the different tourism inputs points out that sustaining long-term levels of economic activity requires careful planning and management. This conclusion is in line with the recommendations made by international organizations, such as the World Tourism Organization, in particular regarding to the tourism development in small island developing states (e.g., Briguglio, 1995; van der Velde et al., 2007; and UNWTO, 2012). Propositions 3 and 4 are consistent as well with the studies supporting ecotourism as a valid strategy to sustain long-term economic activity and environmental quality in this type of tourism-driven destinations (among others, World Bank, 1998; and Huybers and Bennett, 2003; and UNWTO, 2012). 


\section{Dynamics}

Let us now consider the short-run dynamics of the economy. As observed before, we will first reduce the dimension of the dynamical system (9)-(12) by means of specifying the relationship between $k(t)$ and $e(t)$ from the optimal condition $g(e(t), k(t))=0$. Applying the inverse function theorem, one can verify that there exists a unique one-to-one relationship between $k(t)$ and $e(t)$ of the form $k(t)=h(e(t))$ if $f_{e e}^{\prime \prime} f_{k k}^{\prime \prime} \neq f_{k e}^{\prime \prime} f_{e k}^{\prime \prime}$. Even if this condition holds for our technology (2), in general we cannot write $k(t)=h(e(t))$ as a closed-form expression. Still, the implicit function theorem allows us to conclude that $h(e(t))$ is a strictly increasing function of $e(t)$ because $f_{k e}^{\prime \prime}>0$. Moreover, if we assume that the depreciation rate of both physical capital and environmental quality are the same, i.e., $\epsilon=\delta$, it is easy to identify that $k(t)=\frac{1}{\sigma} \frac{\gamma}{\alpha} e(t)$. For $\epsilon \neq \delta$ the relationship $k(t)=h(e(t))$ cannot be explicitly written in terms of $e(t)$ and the underlying parameters. But since the focus of the paper is on the local dynamics, we can alternatively linearize $g(e(t), k(t))=0$ in a neighborhood of the steady-state $\left(e^{*}, k^{*}\right)$ :

Proposition 5. Around the steady-state equilibrium

$$
k(t)=\frac{\epsilon+\rho}{\sigma(\delta+\rho)} \frac{\gamma}{\alpha}\left[\Phi_{1} e(t)+\Phi_{2} e^{*}\right]
$$

where $\Phi_{1} \equiv \frac{\alpha(\delta+\rho)+(1-\alpha)(\epsilon+\rho)}{\gamma(\epsilon+\rho)+(1-\gamma)(\delta+\rho)}$ and $\Phi_{2} \equiv \frac{\beta(\delta-\epsilon)}{\gamma(\epsilon+\rho)+(1-\gamma)(\delta+\rho)}$.

Proof. See Appendix D.

The condition (19) allows us to reduce the dynamical system (9)-(12) to a system of two equations and two unknowns. Considering (12), the Euler condition (9) can be rewritten as

$$
\frac{\dot{c}(t)}{c(t)}=\frac{1}{\xi(c(t))}\left[(\sigma-\vartheta) f_{e}^{\prime}-(\epsilon+\rho)\right] .
$$

If we replace $m(t)$ from 10$)$ in (11), the law of motion of the environmental conditions becomes

$$
\dot{e}(t)=(\sigma-\vartheta) f(e(t), k(t))-\sigma c(t)-\sigma[(\delta+n) k(t)+\dot{k}(t)]-(\epsilon+n) e(t) .
$$

Applying Proposition 5 to (20) and (21), and rearranging terms, we obtain the following reduced-dimension system for $c(t)$ and $e(t)$ :

$$
\begin{gathered}
\frac{\dot{c}(t)}{c(t)}=\frac{1}{\xi(c(t))}\left\{\alpha A(\sigma-\vartheta)\left(\frac{\epsilon+\rho}{\sigma(\delta+\rho)} \frac{\gamma}{\alpha}\right)^{\gamma} e(t)^{-(1-\alpha)}\left[\Phi_{1} e(t)+\Phi_{2} e^{*}\right]^{\gamma}-(\epsilon+\rho)\right\} \\
\frac{\dot{e}(t)}{e(t)}=\left[1+\frac{\gamma(\epsilon+\rho)}{\alpha(\delta+\rho)}\right]^{-1} \times \\
\left\{A(\sigma-\vartheta)\left(\frac{\epsilon+\rho}{\sigma(\delta+\rho)} \frac{\gamma}{\alpha}\right)^{\gamma} e(t)^{-(1-\alpha)}\left[\Phi_{1} e(t)+\Phi_{2} e^{*}\right]^{\gamma}-\sigma \frac{c(t)}{e(t)}-\frac{\gamma(\delta+n)(\epsilon+\rho)}{\alpha(\delta+\rho)}\left[\Phi_{1}+\Phi_{2} \frac{e^{*}}{e(t)}\right]-(\epsilon+n)\right\} .
\end{gathered}
$$


The equations (22) and (23), together with the transversality condition for the environmental quality, describe the optimal behaviour of our economy around the steady-state. Notice that for $\epsilon=\delta$ the system is simpler because we directly know the closed-form expression of the ratio $k(t) / e(t)$. In this particular case the coefficients above reduce to $\Phi_{1}=1$ and $\Phi_{2}=0$. Then, rewriting $(22)$ and $(23)$ we get

$$
\begin{gathered}
\frac{\dot{c}(t)}{c(t)}=\frac{1}{\xi(c(t))}\left\{B(\sigma-\vartheta) e(t)^{(\alpha+\gamma)-1}-(\epsilon+\rho)\right\}, \\
\frac{\dot{e}(t)}{e(t)}=B \frac{\sigma-\vartheta}{\alpha+\gamma} e(t)^{(\alpha+\gamma)-1}-\sigma \frac{\alpha}{\alpha+\gamma} \frac{c(t)}{e(t)}-(\delta+n),
\end{gathered}
$$

where $B \equiv \alpha A\left(\frac{\gamma}{\alpha \sigma}\right)^{\gamma}$.

\section{Dynamic response}

In order to explore the optimal transitional behavior of the economy, and the corresponding stability properties of the steady-state, we will study the dynamical system identified in the previous section. Our framework considers two types of capital (state variables). The physical capital $k(t)$ represents the infrastructure and tourism facilities of the destination, while the environmental conditions are summarized by the natural capital $e(t)$. Both sorts of capital can differ with respect to, among other things, their depreciation rates. One may reasonable assume that the depreciation rate of the natural capital $(\epsilon)$ is low because the average lifetime of this capital can be substantially long. However, this statement is far from obvious when $e(t)$ represents the environmental quality as a tourism input. This could include a variety features such as the beach width, the presence of dune systems or, in general, coastal erosion. In this respect, numerous studies regarding destinations like, for instance, the Caribbean (among others, Cambers, 2009; and Scott et al., 2012) find that climate change, hurricanes and tropical storms have significantly increased coastal and beach erosion, threatening as well many coastal resort properties. Moreover, this trend is likely to continue or even to increase. Thus, in contrast to the former argument, one could consider $\epsilon$ as being of large magnitude.

The discussion above illustrates that it is difficult to unambiguously set the parameter $\epsilon$ and, hence, to compare it with $\delta$, the depreciation rate of the physical capital. In our analysis we first consider the case $\epsilon \neq \delta$, where the system $(22)-(23)$ above describes the dynamics of the economy. As frequently done in growth theory (e.g., Barro and Sala-iMartin, 2004; and Acemoglu, 2009), we then eliminate this exogenous source of capital heterogeneity in order to distinguish the main mechanisms at play. More specifically, assuming that $\epsilon=\delta$ allows us to concentrate on the impact of tourism as an endogenous source of depreciation of the environmental quality. Taking advantage of the greater 
analytical tractability of the corresponding dynamical system (24)-(25), we will be able to identify additional dynamic mechanisms affecting, in particular, the intergenerational welfare. We finally complete the description of the short-run dynamics of the economy by studying, for both cases, the possibility of imbalance effects.

\subsection{Transitional dynamics}

The log-linearization of the system $(22)-(23)$ around the steady-state described in Proposition 3 yields the linear differential system (in matrix form):

$$
\left[\begin{array}{c}
\dot{\tilde{e}}(t) \\
\dot{\tilde{c}}(t)
\end{array}\right]=J \times\left[\begin{array}{c}
\tilde{e}(t) \\
\tilde{c}(t)
\end{array}\right]+\left[\begin{array}{c}
-\Omega_{1} \tilde{e}-\Omega_{2} \tilde{c} \\
-v_{1} \tilde{e}
\end{array}\right],
$$

where $\tilde{e}(t)$ and $\tilde{c}(t)$ denote the $\log$ of $e(t)$ and $c(t)$ respectively, and $J$ is the Jacobian matrix evaluated at the steady-state:

$$
J \equiv\left[\begin{array}{cc}
\Omega_{1} & \Omega_{2} \\
v_{1} & 0
\end{array}\right]
$$

with

$$
\begin{gathered}
\Omega_{1} \equiv\left[1+\frac{\gamma(\epsilon+\rho)}{\alpha(\delta+\rho)} \Phi_{1}\right]^{-1}\left\{\left(\alpha+\gamma \Phi_{1}\right) \frac{\epsilon+\rho}{\alpha}-\left[\frac{\gamma(\delta+n)(\epsilon+\rho)}{\alpha(\delta+\rho)}\left(1-\Phi_{2}\right)+(\epsilon+n)\right]\right\}, \\
\Omega_{2} \equiv\left[1+\frac{\gamma(\epsilon+\rho)}{\alpha(\delta+\rho)} \Phi_{1}\right]^{-1}\left\{(\epsilon+n)-\frac{\epsilon+\rho}{\alpha}\left[\frac{(\delta+\rho)-\gamma(\delta+n)}{\delta+\rho}\right]\right\} \\
v_{1} \equiv \frac{1}{\theta}(\epsilon+\rho)\left[\gamma \Phi_{1}-(1-\alpha)\right] .
\end{gathered}
$$

For this system the two eigenvalues of the matrix $J$, which will be denoted by $\bar{\alpha}_{i}$ with $i=\{1,2\}$, are

$$
\bar{\alpha}_{i}=\frac{1}{2}\left(\Omega_{1} \pm \sqrt{\Omega_{1}^{2}+4 v_{1} \Omega_{2}}\right) .
$$

Let us consider the case $\epsilon \neq \delta$. Characterizing the determinant and trace of the matrix $J$, we can establish the stability properties of the long-run equilibrium. The following proposition summarize this outcome:

Proposition 6. For $\delta>\epsilon$, the steady-state is saddle-path stable iff $\gamma<\bar{\gamma}$. For $\delta<\epsilon$, the steady-state is saddle-path stable iff $\gamma>\bar{\gamma}$ and $\alpha>\bar{\alpha}$. The steady-state is unstable otherwise. Moreover, when the steady-state is saddle-path stable, the economy does not exhibit complex dynamics.

Proof. See Appendix E. 
The proposition shows that the steady-state cannot be stable. Then, local indeterminacy and, consequently, infinite optimal trajectories are not possible provided the initial conditions for the state variables. There is instead a unique optimal transition path (i.e., saddle-path stability). This property states that the steady-state equilibrium identified in Proposition 3 is saddle-path stable. We can therefore conclude that it is possible to sustain a long-term level of tourism activities that is compatible with the conservation of the environmental quality of the economy. The saddle-path property of the stability result implies that the optimal trajectory is unique. Thus, consistently with the general conclusion of Section 4, in this economy sustainability requires an attentive supervision by the policy maker of the provision of tourism services. In particular, as noticed in Section 4, it is crucial to ensure a proper proportion of physical capital and environmental quality along the transition path, which are fundamental ingredients for attracting tourism and, therefore, to guarantee the economic activity of the destination.

However, this property depends on the relative importance of each type of capital as a tourism input. If physical capital depreciates more than the exogenous deterioration of environmental quality $(\epsilon<\delta)$, the economy can have saddle-path stability. This is only possible though if the importance of physical capital in the provision of tourism services is low $(\gamma<\bar{\gamma})$. Notice that this case includes the possibility of considering that the environment deteriorates only due to the negative effect of tourism, that is to say, $\epsilon=0$ in our model.$^{6}$ With respect to the situation where the depreciation rate is greater for the environmental quality than for the physical capital $(\epsilon>\delta)$, the steady-state can be saddle-path stable as well. But this time this is only possible if the weight of physical capital is big enough $(\gamma>\bar{\gamma})$. For this case we also require that the weight of the environmental quality is high $(\alpha>\bar{\alpha})$ in order to ensure that a well-defined threshold value $\bar{\gamma}<1$. We should additionally observe that the convergence to the steady-state does not exhibits cycles either:7

Let us focus now on the impact of tourism as an endogenous source of depreciation for the environmental capital. As observed before, we assume in this respect that $\epsilon=\delta$ in order to eliminate the exogenous source of capital depreciation heterogeneity. Due to the greater analytical tractability of this case, one can easily set a phase diagram to provide a qualitative description of the dynamics of the economy. Figure 1 depicts the phase diagram for the system (24)-(25). From equation (24), we directly identify the locus where $\dot{c}(t)=0$ (vertical line in Figure 1), which is given by $e(t)=e^{*}$. By fixing

\footnotetext{
${ }^{6}$ All the results of the paper are valid for $\epsilon=0$, keeping unchanged the conditions about the other parameters of the model.

${ }^{7}$ As we show in Appendix E, if the eigenvalues of the corresponding Jacobian matrix are complex the steady-state is unstable.
} 


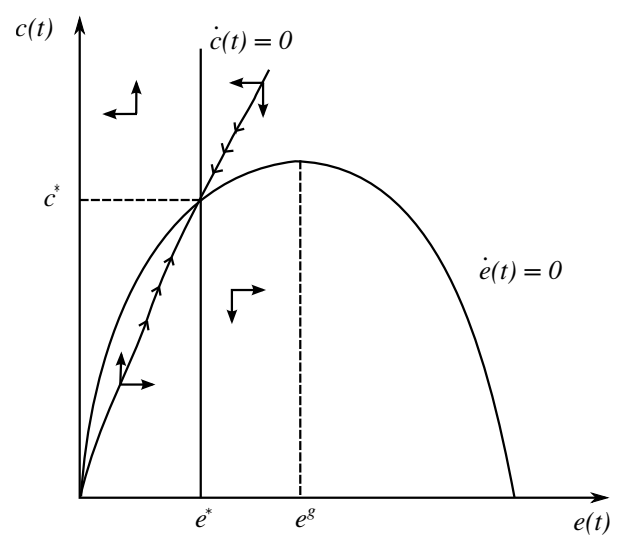

Figure 1: Phase diagram.

$c(t)=\bar{c}$ in (24), one can conclude that $\partial \dot{c}(t) / \partial e(t)<0$ and, therefore, the direction of motion. The locus where $\dot{e}(t)=0$ is determined from the other differential equation (25):

$$
c(t)=\frac{1}{\sigma} \frac{\alpha+\gamma}{\alpha}\left[B \frac{\sigma-\vartheta}{\alpha+\gamma} e(t)^{\alpha+\gamma}-(\delta+n) e(t)\right]
$$

which is a concave function, where $e^{g}$ in Figure 1 represents the level of environmental quality that maximizes the steady-state consumption per capital, i.e., the golden rule environmental conditions. Since $B(\sigma-\vartheta) e^{*(\alpha+\gamma)-1}=(\epsilon+\rho)$ and $B(\sigma-\vartheta) e^{g(\alpha+\gamma)-1}=(\epsilon+n)$, one should observe that $e^{*}<e^{g}$ because we have assumed that in our economy $\rho>n$ (see Section 3). Finally, the direction of motion is determined by fixing $e(t)=\bar{e}$ in (25), and concluding afterwards that $\partial \dot{e}(t) / \partial c(t)<0$. Drawing the two loci together in Figure 1. we clearly see that the economy optimally follows a unique stable manifold (saddlepath stability), monotonically converging to the steady-state identified in Proposition 3$]^{8}$ Then, the steady-state is saddle-path stable. As in the previous case, this implies that it is possible to sustain a long-term level of tourism that is compatible with the conservation of the environmental quality of the economy, and that the optimal trajectory is unique.

We can analytically confirm this conclusion by log-linearizing the system (24)-(25):

$$
\left[\begin{array}{c}
\dot{\tilde{e}}(t) \\
\dot{\tilde{c}}(t)
\end{array}\right]=J \times\left[\begin{array}{c}
\tilde{e}(t) \\
\tilde{c}(t)
\end{array}\right]+\left[\begin{array}{c}
-(\rho-n) \tilde{e}^{*}-\left[(\epsilon+n)-\frac{\epsilon+\rho}{\varphi}\right] \tilde{c}^{*} \\
\frac{1}{\theta}(1-\varphi)(\epsilon+\rho) \tilde{e}^{*}
\end{array}\right],
$$

where $\varphi \equiv \alpha+\gamma$ and

$$
J \equiv\left[\begin{array}{cc}
(\rho-n) & (\epsilon+n)-\frac{\epsilon+\rho}{\varphi} \\
-\frac{1}{\theta}(1-\varphi)(\epsilon+\rho) & 0
\end{array}\right] .
$$

\footnotetext{
${ }^{8}$ Notice that transitional paths outside the stable manifold are not optimal because they would violate feasibility and TC. Regarding TC, let us observe that $(\sigma-\vartheta) f_{e}^{\prime}(\bar{e})<\epsilon+n$ for every constant $\bar{e}>e^{g}$ since $f_{e}^{\prime}(e(t))=B e(t)^{(\alpha+\gamma)-1}$.
} 
The two eigenvalues of $J$ are

$$
\bar{\alpha}_{i}=\frac{1}{2}\left\{(\rho-n) \pm \sqrt{(\rho-n)^{2}+\frac{4(1-\varphi)(\epsilon+\rho)}{\theta}\left[\frac{\epsilon+\rho}{\varphi}-(\epsilon+n)\right]}\right\} .
$$

One can verify that the expression inside the square root is strictly positive because the term between the square brackets is strictly positive. Hence, both eigenvalues are real. Moreover, if we denote by $\bar{\alpha}_{1(2)}$ the eigenvalue corresponding to the positive (negative) sign in front of the square root, we can see that $\bar{\alpha}_{1}>0$ and $\bar{\alpha}_{2}<0.9$ We can then establish the saddle-path property of the steady-state:

Proposition 7. The Jacobian matrix of the linearized system (33) has two real eigenvalues, one positive and the other negative. Therefore, for $\epsilon=\delta$, the economy exhibits saddle-path stability (unique stable manifold).

Knowing the eigenvalues $\bar{\alpha}_{i}$, we can identify a closed-form expression for the optimal trajectory of our economy and the corresponding speed of convergence:

Proposition 8. For $\epsilon=\delta$, the optimal trajectory of the economy is given by

$$
\begin{gathered}
\tilde{e}(t)=\left[\tilde{e}(0)-\tilde{e}^{*}\right] \exp \left\{\bar{\alpha}_{2} t\right\}+\tilde{e}^{*}, \\
\tilde{c}(t)=\frac{v_{22}}{v_{12}}\left[\tilde{e}(0)-\tilde{e}^{*}\right] \exp \left\{\bar{\alpha}_{2} t\right\}+\tilde{c}^{*},
\end{gathered}
$$

where the coordinates of the eigenvector $\left(v_{12}, v_{22}\right)$ corresponding to $\bar{\alpha}_{2}$ verify that $v_{22} / v_{12}=$ $-(1-\varphi)(\epsilon+\rho) / \bar{\alpha}_{2} \theta>0$. The speed of convergence of the economy is $\bar{\beta} \equiv-\bar{\alpha}_{2}$. Then, the time that the economy needs to reduce by half the difference with respect to the steady-state is $\bar{t} \equiv-\log (1 / 2) / \bar{\beta}$.

\section{Proof. See Appendix F}

The proposition explicitly shows that the optimal trajectory of the economy exists and is unique, converging to the long-run equilibrium without cycles. The rate at which the economy (in level terms) approaches to this steady-state is given by $\bar{\beta}$. Notice that the analytical tractability of this case allows us to further investigate the speed of convergence of the economy, which is given by the eigenvalue $\bar{\alpha}_{2}$ from $(35)$. Therefore, in what follows, we complete the analysis introduced in Section 4 about ecotourism by studying the effect of promoting this type of tourism on the rapidity of the development of the destination.

As pointed out before, in the context of our model implementing ecotourism is represented by a decrease of $\vartheta$ simultaneously with an increase of $\alpha$. That is to say, ecotourists

\footnotetext{
${ }^{9}$ It is easy to see that $\operatorname{det}(J)<0$. Since $\operatorname{det}(J)=\bar{\alpha}_{1} \bar{\alpha}_{2}$ we can conclude that one the real eigenvalues is positive while the other is negative. Therefore, $\bar{\alpha}_{1}>0$ and $\bar{\alpha}_{2}<0$ because $\bar{\alpha}_{1}>\bar{\alpha}_{2}$ from (35).
} 
concentrate on activities with low environmental impact and, at the same time, they give greater importance to the environmental conditions of the destination. Let us investigate the effect of reducing $\vartheta$ together with a raise of $\alpha$ on the speed of convergence of the economy. Since the speed of convergence $\bar{\beta}=-\bar{\alpha}_{2}$, taking into account (35), one can verify that implementing ecotourism reduces $\bar{\beta}$. Indeed, $\vartheta$ does not affect the speed of convergence due to the local approach of our dynamic analysis. One can easily verify that, in a neighbourhood of the steady-state, the effect of $\vartheta$ is compensated for by the response of $e^{*}$ and $c^{*}{ }^{10}$ Nevertheless, one can verify that ecotourism still affects the speed of convergence through its other dimension: $\partial \bar{\beta} / \partial \alpha<0$.

Due to the greater importance that ecotourists give to the environmental conditions of the destination (i.e., a larger $\alpha$ ), the policy maker should be particularly attentive to the expansion of tourism activity and the subsequent environmental degradation. Thus, the balanced dynamic relationship between physical capital and environmental conditions $\left(k(t)=\frac{1}{\sigma} \frac{\gamma}{\alpha} e(t)\right.$ for all $\left.t \geq 0\right)$ would require a slower development of the economy. Considering the conditions provided in Proposition 4, we can summarize the dynamic results regarding to ecotourism:

Proposition 9. For $\epsilon=\delta$, a destination promoting sufficiently environmental-friendly tourism (i.e., $\alpha>\bar{\alpha}$ and $\vartheta<\bar{\vartheta}$ ) increases its long-term welfare. Nevertheless, the convergence to the steady-state will be slower.

From a policy perspective, this outcome reveals a social cost of ecotourism. In our stylized model we have assumed that promoting this type of tourism does not imply any additional monetary cost to the economy. However, one should observe that ecotourism can be costly in terms of intergenerational welfare. Let us consider a developing destination, where consumption per capita is lower than its long-run level, i.e., $c(0)<c^{*}$. As we know from our previous results, ecotourism allows the economy to achieve a higher long-term welfare. But due to the slower convergence, this policy would affect the intergenerational equity, inducing a welfare sacrifice of the current generations in favour of the future ones. Even if beyond the scope of our paper, this result will be particularly relevant when the policy maker can endogenously choose the type of tourists that she wants to attract (see Concluding remarks). In such a problem, the choice of the optimal type of tourism would depend on the relative importance that a society gives to the welfare of current and future generations.

\footnotetext{
${ }^{10}$ Our linearization around the steady-state implies that $B \frac{\sigma-\vartheta}{\alpha+\gamma} \exp \left\{-(1-\varphi) \tilde{e}^{*}\right\}-\frac{\alpha}{\alpha+\gamma} \sigma \exp \left\{\tilde{c}^{*}-\tilde{e}^{*}\right\}=$ $\epsilon+n$ and $B(\sigma-\vartheta) \exp \left\{-(1-\varphi) \tilde{e}^{*}\right\}=\epsilon+\rho$. Then, for fixed $\epsilon, n$ and $\rho$, the effect of $\vartheta$ should be exactly compensated by the variation of $e^{*}$ and $c^{*}$.
} 


\subsection{Imbalance effect}

We finish our description of the dynamics by identifying the existence of an imbalance effect, which is related to the optimal proportion between tourism infrastructures and environmental quality. We have seen in Proposition 1 that the policy maker should ensure a proper proportion of inputs for tourism, verifying $g(k(t), e(t))=0$ in every moment of time. This optimal condition implies that $k(t)=h(e(t))$ for all $t \geq 0$, being $h(e(t))$ an increasing function of $e(t)$. In particular, the optimal proportion of inputs can be explicitly set for the case of homogenous capital depreciation $(\epsilon=\delta)$, where the ratio $k(t) / e(t)$ equals a fixed constant $\gamma / \alpha \sigma$.

However, since the initial endowment of physical capital and environmental quality are intrinsic characteristics of the destination, nothing prevents us from having $k(0) \neq$ $h(e(0))$. In this situation an imbalance effect arises if physical capital investment and environmental maintenance are assumed not to be negative, i.e., $i(t) \geq 0$ and $m(t) \geq 0$ for all $t \geq 0$. This is the case of irreversible investments in physical capital and environmental quality. As we will show in the next proposition, under the presence of this imbalance effect the economy will reestablish the optimal proportion between $k(t)$ and $e(t)$ during a finite number of periods $T$. Once the relationship $k(t)=h(e(t))$ is recovered the economy will behave as detailed before, starting instead at time $T$. Notice that we do not assume any specific relationship between $\epsilon$ and $\delta$ for our proposition. The result is valid for both, homogenous and heterogenous capital depreciation:

Proposition 10. If $k(0)<h(e(0))$, $i(t)>0$ for $t \geq 0$, whereas $m(t)=0$ for $0 \leq t \leq$ $T<\infty$ and $m(t)>0$ for $t>T$. If $k(0)>h(e(0)), m(t)>0$ for $t \geq 0$, whereas $i(t)=0$ for $0 \leq t \leq T<\infty$ and $i(t)>0$ for $t>T$.

Proof. See Appendix G.

This proposition is particularly useful to understand the dynamics of tourism-driven developing economies, where the environmental quality is an important feature for attracting tourism. This is often the case of beach destinations in developing countries. These types of locations are frequently endowed with high environmental quality, which contrasts with their lack of infrastructures and tourism facilities. In our set-up these economies are identified as unbalanced situations, where the initial endowment of physical capital is relatively small with respect to the environmental capital. Since $h(e(t))$ is an increasing function (see Section 5), we are in the case $k(0)<h(e(0))$ of the proposition. According to this, the destination optimally sacrifices part of its environmental endowment during the initial stages of development, concentrating on the accumulation of physical capital (that is to say, $i(t)>0$ for $t \geq 0$, whereas $m(t)=0$ for $0<t \leq T$ ). 
The economy temporally focuses on the creation of basic infrastructures, providing fundamental inputs to supply tourism services. After this transitional phase, however, the economy invests as well in pollution abatement since tourists are also attracted by the environmental conditions. This complementary effort allows the destination to ensure the sustainability of the economic activity. More specifically, once the balance between environmental quality and physical capital is recovered (i.e., $k(t)=h(e(t)))$, the optimal dynamical behaviour of the economy from then on follows what was described in the previous section, investing in environmental maintenance too (i.e., $i(t)>0$ and $m(t)>0$ for $t>T)$.

As pointed out in the Introduction, this transitional phase has been empirically identified by many papers. The main feature of this readjusting period is that a developing destination temporally renounces part of its large environmental quality, focusing on the provision of primary tourist infrastructures, such as airports, roads, cruise docks, and hotels, etc. Nevertheless, the aforementioned studies also observed that several of these regions invested too fast in physical capital in order to increase tourism activity, disregarding the negative effect on the environmental inputs. The lack of planning and inadequate understanding of the dynamic interaction between tourism and the environmental quality has frequently caused important threats to the sustainability of tourism and economic activity in numerous destinations.

Let us finally observe that this readjusting phase can also be linked to the emergence of an environmental Kuznet curve (EKC), which in our paper is related to the dynamic interaction between tourism and the environmental quality 11 An economy endowed with rich environmental conditions, during initial stages of development, optimally sacrifices part of the environmental quality. Temporally focusing on the creation of basic physical structures, the economy provides fundamental inputs to supply tourism services. However, since tourists are also attracted by the environmental quality, the economy should invest as well in environmental maintenance after this transitional phase in order to ensure the sustainability of this economic activity. This behaviour of the economy clearly displays an initial deterioration of the environmental conditions of the economy, followed by a recovery once the economy reaches a high enough development. Then, a Kuznet-

\footnotetext{
${ }^{11}$ See Kijima et al. (2010) for a recent survey about the theoretical models for the EKC. Following their characterization, our paper identifies a theoretical explanation for the EKC that is based on the reallocation of resources between consumption and abatement. Within this context, but in contrast to many models, we do not need to directly include pollution or environmental quality in the consumers' preferences. Tahvonen and Salo (2001) do not incorporate the environmental conditions in the utility function. However, they include the possibility of a technological choice of alternative energy resources, which turns out to be a source of EKC.
} 
type evolution of the environmental quality can arise as a result of the optimal behaviour of small tourism economies, where the provision of tourism services is importantly driven by both environmental quality and physical capital.

\section{Concluding remarks}

The aim of the paper was to study the reciprocal causality between tourism and environmental quality. We introduced in this respect a theoretical framework to investigate the dynamic implications of this relationship. We found that, by investing in pollution abatement activities that are sufficiently efficient, tourism can guarantee positive longterm levels of environmental quality, income and welfare. We demonstrated, in particular, that ecotourism allows the economy to raise these levels but at the cost of a slower economic development. We also identified the importance of maintaining an optimal balance between physical capital and environmental quality along the evolution of the economy. Thus, careful planning and management would be required in order to sustain economic activity and welfare by means of tourism. We detected as well the presence of imbalance effects behind the optimal proportion of physical and natural capital. Consequently, during initial stages of its development a destination endowed with rich environmental conditions can optimally sacrifice part of the environmental quality, temporally focusing on building basic infrastructures for tourism.

Our model is highly stylized in order to underline the main dynamic mechanisms at play. Several limitations can then arise, mainly related to the inclusion of additional effects. In contrast to papers such as Marsiglio (2015 and 2017), we do not allow for exogenous renovation of the environmental quality (see Section 3). Still, the case of $\epsilon<0$ could be studied with our set-up by assuming that the discount rate $\rho$ is big enough (i.e., $\rho+\epsilon>0)$, together with positive conditions for our variables. Natural renovation would introduce even richer dynamics because of its interaction with the opposite mechanism of physical capital depreciation. As in our paper, the relative size of $\epsilon$ with respect to $\delta$ would be crucial to ensure the (saddle-path) stability of the long-run equilibrium. From the intertemporal welfare perspective, our theoretical framework identifies a social welfare cost of ecotourism in terms of intergenerational equity. This cost results from the slower optimal development of destinations promoting this type of tourism. A possible direction for further research may explicitly include the choice of the type of tourism, which would allow us to endogenize the parameters $\alpha$ and/or $\vartheta$ of our set-up. In particular, if the policy maker opts for promoting a type of tourism with high environmental content, she should also take into account the intergenerational welfare consequences of the subsequent slower convergence. 
Regarding to the society's preferences, we have focused on situations where the environmental conditions do not enter directly into the utility function (see Footnote 4). A low taste for the environmental quality can be associated to developing economies (a typical rationalization is provided by the EKC). However, it could be interesting to understand the formation of environmental tastes in these destinations (e.g., Grossman and Krueger, 1995; or Schumacher, 2015). Another limitation from the point of view of development economics is that our destinations fully rely on tourism. This rather extreme situation allowed us to highlight the interaction between tourism and environmental quality. Still, this is the case of many tourism-driven developing areas, which they show difficulties in diversifying the economic activity (see Section 3). In order to better understand cases of developed beach destinations in countries like Spain, or the prospect of development in areas such as the Caribbean, it would be interesting to study the role played by economic diversification. A possibility in this respect would be to integrate our model into an international trade framework (see, for instance, Copeland and Taylor, 2001). Let us finally point out the generality of our approach. The model assumes that the whole stock of environmental capital is used as a production input. Our paper considers in this respect the specific case of environmental quality, where tourists are attracted by the environmental stock of the destination. Nevertheless, this idea also applies to problems in agricultural economics. For instance, the concept of environmental capital considered in this paper can be adapted to describe the evolution of biodiversity as an agricultural input. Our framework could then also be useful to understand the dynamic interaction between agricultural production and biodiversity (e.g., Polasky et al., 2005).

\section{Appendices}

\section{A Proposition 1 proof}

The FOC for $c(t)$ and $m(t)$ yield $\lambda(t)=u^{\prime}(c(t))$ and $\lambda(t)=\sigma \mu(t)$. Taking this into the FOC for $e(t)$ and $k(t)$ we obtain

$$
\begin{aligned}
-\frac{\dot{\mu}(t)}{\mu(t)} & =(\sigma-\vartheta) f_{e}^{\prime}-(\epsilon+\rho), \\
-\frac{\dot{\lambda}(t)}{\lambda(t)} & =\frac{\sigma-\vartheta}{\sigma} f_{k}^{\prime}-(\delta+\rho) .
\end{aligned}
$$

Since $\lambda(t)=\sigma \mu(t)$,

$$
\frac{\dot{\lambda}(t)}{\lambda(t)}=\frac{\dot{\mu}(t)}{\mu(t)}
$$


Moreover, knowing that $\lambda(t)=u^{\prime}(c(t))$,

$$
\frac{\dot{\lambda}(t)}{\lambda(t)}=\frac{u^{\prime \prime}(c(t)) c(t)}{u^{\prime}(c(t))} \frac{\dot{c}(t)}{c(t)}
$$

Then, considering A.1 - A.4 , we get the conditions of the proposition. Notice that (13) and (14) are obtained from the standard transversality conditions

$$
\begin{aligned}
& \lim _{t \rightarrow \infty} \mu(t) e(t) \exp \{-(\rho-n) t\}=0, \\
& \lim _{t \rightarrow \infty} \lambda(t) k(t) \exp \{-(\rho-n) t\}=0,
\end{aligned}
$$

provided that, from the previous results, $\mu(t)=\mu(0) \exp \left(-\int_{0}^{t}\left[(\sigma-\vartheta) f_{e}^{\prime}-\epsilon-n\right] d s\right)$ and $\mu(0)=\frac{1}{\sigma} u^{\prime}(c(0))$.

\section{B Proposition 3 proof}

At the steady-state $\dot{c}(t)=0$. Then, since $\xi(c(t)) \neq 0$, equations $(9)$ and $(12)$ imply that

$$
f_{e}^{\prime *}=\frac{\epsilon+\rho}{\sigma-\vartheta}
$$

and

$$
f_{k}^{\prime *}=\frac{\sigma}{\sigma-\vartheta}(\delta+\rho) .
$$

Since $f_{e}^{\prime}>0$ and $f_{k}^{\prime}>0$ for all $e(t)$ and $k(t)$, we will need that $\vartheta<\sigma$. Using (2) in (A.7) and (A.8), we directly obtain the unique steady-state (15) and (16), where $e^{*}>0$ and $k^{*}>0$. Equations 17 and 18 result from 10 and 11 when $\dot{k}(t)=0$ and $\dot{e}(t)=0$. Notice that, since $e^{*}>0$ and $k^{*}>0$, equation (17) allows us to conclude that $m^{*}>0$. Moreover, replacing $m^{*}$ in (18) from (17), together with the condition (16), yields

$$
c^{*}=\frac{1}{\sigma} e^{*}\left[\frac{\epsilon+\rho}{\alpha}-\frac{\gamma(\epsilon+\rho)(\delta+n)}{\alpha(\delta+\rho)}-(\epsilon+n)\right] .
$$

It is easy to verify that the term between brackets is strictly positive. Then, $c^{*}>0$ because $e^{*}>0$.

\section{Proposition 4 proof}

We study the effect of decreasing $\vartheta$ simultaneously with an increase of $\alpha$ (i.e., the adoption of environmental-friendly tourism in the context of our model) on the steady-state equilibrium identified in Proposition 3 .

For a steady-state variable $x^{*}=\left\{e^{*}, k^{*}, y^{*}, c^{*}\right\}, d x^{*}=\left(\partial x^{*} / \partial \vartheta\right) d \vartheta+\left(\partial x^{*} / \partial \alpha\right) d \alpha$. We know from before that $\partial x^{*} / \partial \vartheta<0$. Then, $\left(\partial x^{*} / \partial \vartheta\right) d \vartheta>0$ for a decreasing $\vartheta$. We just 
need to verify that $\partial x^{*} / \partial \alpha>0$ in order to ensure that increasing $\alpha$ reinforces the positive effect of decreasing $\vartheta$ on $x^{*}$. Considering the close-form expression for $e^{*}$, we can see that $\partial e^{*} / \partial \alpha>0$ for $\alpha>\bar{\alpha}$ where

$$
\bar{\alpha} \equiv\left[\frac{1}{A(\sigma-\vartheta)}\right]^{\frac{1}{1-\gamma}}\left[\frac{\sigma(\delta+n)}{\gamma}\right]^{\frac{\gamma}{1-\gamma}}(\epsilon+\rho) .
$$

Under this condition, $\partial k^{*} / \partial \alpha>0$ as well. Moreover, since $y^{*}=f\left(e^{*}, k^{*}\right)$, we can confirm that $\partial y^{*} / \partial \alpha>0$ because $f_{i}^{\prime}>0$. Let us study the sign of $\partial c^{*} / \partial \alpha$. We define the elasticity of $e^{*}$ with respect to $\alpha$ as $E \equiv \frac{\partial e^{*}}{\partial \alpha} \frac{\alpha}{e^{*}}$. Taking Equation 16$)$ and rewriting the $\partial c^{*} / \partial \alpha$ in terms of $E$, we can state that $\partial c^{*} / \partial \alpha>0$ iff the elasticity $E>\bar{E}$, for $\bar{E} \equiv \frac{\bar{A}}{\bar{A}-(\epsilon+n)}$ where $\bar{A}$ is the following combination of parameters of our model:

$$
\bar{A} \equiv \frac{\epsilon+\rho}{\alpha}\left(1-\gamma \frac{\delta+n}{\delta+\rho}\right) .
$$

Notice that $\bar{E}>0$ because $c^{*}>0$. Moreover, $\bar{A}>0$ because we have assumed that $\rho>n$ (see Equation 6). Since $\bar{E}$ does not depend on $\vartheta$, and $\frac{\partial E}{\partial \vartheta}=-\frac{\alpha}{(1-\alpha-\gamma)(\sigma-\vartheta)}<0$, the condition $E>\bar{E}$ holds if $\vartheta$ is low enough. Consequently, $\partial c^{*} / \partial \alpha>0$ for $\vartheta<\bar{\vartheta}$. The threshold $\bar{\vartheta}$ is just the value of $\vartheta$ such that $E=\bar{E}$, that is to say,

$$
\frac{1-\gamma}{1-\alpha-\gamma}+\frac{\alpha}{(1-\alpha-\gamma)^{2}} \log \left[A\left(\frac{\gamma}{\delta+\rho}\right)^{\gamma}\left(\frac{\alpha}{\epsilon+\rho}\right)^{1-\gamma} \sigma^{-\gamma}(\sigma-\bar{\vartheta})\right]=\bar{E} .
$$

Rearranging terms in this expression, we can conclude that $\bar{\vartheta}=\sigma-\exp \{\Upsilon\}$ where $\Upsilon$ is defined as

$$
\Upsilon \equiv \frac{(1-\alpha-\gamma)^{2}}{\alpha}\left[\bar{E}-\frac{1-\gamma}{1-\alpha-\gamma}\right]-\log \left[A\left(\frac{\gamma}{\delta+\rho}\right)^{\gamma}\left(\frac{\alpha}{\epsilon+\rho}\right)^{1-\gamma} \sigma^{-\gamma}\right] .
$$

Finally, we have to ensure that $\bar{\vartheta}>0$ since $\vartheta$ is a positive parameter in our model. In this respect the inequality $\sigma>\exp \{\Upsilon\}$ must hold. Taking the previous expression for $\Upsilon$, and rearranging terms in the inequality, we can identify a threshold value so that $\sigma>\bar{\sigma}$ :

$$
\bar{\sigma}=\exp \left\{\frac{1}{1-\gamma}\left\{\frac{(1-\alpha-\gamma)^{2}}{\alpha}\left[\bar{E}-\frac{1-\gamma}{1-\alpha-\gamma}\right]-\log \left[A\left(\frac{\gamma}{\delta+\rho}\right)^{\gamma}\left(\frac{\alpha}{\epsilon+\rho}\right)^{1-\gamma}\right]\right\}\right\}
$$

In Proposition 3, we have already observed that the efficiency of maintenance must be large enough $(\sigma>\vartheta)$. We then just need to set $\sigma>\max \{\vartheta, \bar{\sigma}\}$ in order to ensure that $\bar{\vartheta}>0$. Notice that, once $\partial c^{*} / \partial \alpha>0$ is ensured, the effect of $\vartheta$ on $c^{*}$ will be reinforced. Consequently, the increase of the long-run welfare of the economy will be greater as well.

\section{Proposition 5 proof}

Let us consider the definition of $g(e(t), k(t))$ in Proposition 1. We do a first-order approximation of this function around the steady-state equilibrium $\left(e^{*}, k^{*}\right)$ :

$$
g(e(t), k(t)) \approx g\left(e^{*}, k^{*}\right)+g_{e}^{\prime}\left(e^{*}, k^{*}\right)\left[e(t)-e^{*}\right]+g_{k}^{\prime}\left(e^{*}, k^{*}\right)\left[k(t)-k^{*}\right] .
$$


From the characterization of the steady-state in Proposition 3 , since $g\left(e^{*}, k^{*}\right)=0$, the linearization yields:

$g(e(t), k(t)) \approx \frac{1}{k^{*}}[\gamma(\epsilon+\rho)+(1-\gamma)(\delta+\rho)] k(t)-\frac{1}{e^{*}}[(1-\alpha)(\epsilon+\rho)+\alpha(\delta+\rho)] e(t)+\beta(\epsilon-\delta)$.

Taking $g(e(t), k(t))=0$ in A.16, and $k^{*}=\frac{\epsilon+\rho}{\sigma(\delta+\rho)} \frac{\gamma}{\alpha} e^{*}$ from Proposition 3, we obtain the relationship (19) of the proposition.

\section{E Proposition 6 proof}

Let us study the sign of $\Omega_{1}, \Omega_{2}$ and $v_{1}$ in order to identify the stability properties of the steady-state. Taking the definition of $\Omega_{1}$, we can show by contradiction that $\Omega_{1}$ is a strictly positive constant. Regarding the sign of $\Omega_{2}$, we additionally define

$$
\begin{gathered}
\bar{\gamma} \equiv \frac{\delta+\rho}{\delta+n}-\alpha \frac{\delta+\rho}{\delta+n} \frac{\epsilon+n}{\epsilon+\rho}, \\
\bar{\alpha} \equiv \frac{\rho-n}{\delta+\rho} \frac{\epsilon+n}{\epsilon+\rho}
\end{gathered}
$$

which are strictly positive constants. Moreover, since $\rho>n$, it is easy to see that $\bar{\alpha}<1$. We can then conclude that:

- If $\gamma=\bar{\gamma}$ and $\alpha>\bar{\alpha}$ then $\Omega_{2}=0$.

- If $\gamma<\bar{\gamma}$ then $\Omega_{2}<0$.

- If $\gamma>\bar{\gamma}$ and $\alpha>\bar{\alpha}$ then $\Omega_{2}>0$.

Notice that the condition for $\alpha$ is required in order to ensure that $\bar{\gamma}<1$. Indeed, if $\alpha \leq \bar{\alpha}$ then $\bar{\gamma} \geq 1(=1$ if $\alpha=\bar{\alpha})$. Then $\gamma \in(0,1)$ would be smaller than $\bar{\gamma}$, which is the case corresponding to $\Omega_{2}<0$. Considering the definition of $v_{1}$, since $\Phi_{1}+\Phi_{2}=1$, we can also show that:

- If $\delta>\epsilon$ then $v_{1}<0$.

- If $\delta<\epsilon$ then $v_{1}>0$.

We put together the previous conclusions about the signs of $\Omega_{1}, \Omega_{2}$ and $v_{1}$. Let us first consider the case $\delta>\epsilon$. For this situation we proved above that $v_{1}<0$. If we additionally include the condition $\gamma<\bar{\gamma}$ we know that $\Omega_{2}<0$. Then, the eigenvalues are real and, moreover, $\operatorname{det}(J)<0$. Since $\operatorname{det}(J)=\bar{\alpha}_{1} \bar{\alpha}_{2}$ the steady-state will be saddlepath stable. If we assume instead that $\gamma>\bar{\gamma}$, together with $\alpha>\bar{\alpha}$, then $\Omega_{2}>0$ and $\operatorname{det}(J)>0$. Moreover, the eigenvalues can be complex. For the case of real eigenvalues the steady-state is not saddle-path stable because $\left(\bar{\alpha}_{1}, \bar{\alpha}_{2}\right)>0$ or $\left(\bar{\alpha}_{1}, \bar{\alpha}_{2}\right)<0$. This corresponds, respectively, to the situations of instability or stability. $\operatorname{Since} \operatorname{tr}(J)=\bar{\alpha}_{1}+\bar{\alpha}_{2}$, 
the steady-state is unstable because $\operatorname{tr}(J)=\Omega_{1}>0$. For the case of complex eigenvalues, the steady-state is unstable too because the real part of $\bar{\alpha}_{i}$ is $\Omega_{1}>0$.

Following a similar reasoning we obtain the set of results for $\delta<\epsilon$. For this case $v_{1}>0$. If $\gamma>\bar{\gamma}$ and $\alpha>\bar{\alpha}$ then $\Omega_{2}>0$. Moreover, the eigenvalues are real and the steady-state is saddle-path stable. However, if $\gamma<\bar{\gamma}$ then $\Omega_{2}<0$. If the eigenvalues are real, the steady-state is unstable because $\operatorname{det}(J)<0$ and $\operatorname{tr}(J)>0$. If the eigenvalues are complex, the steady-state is unstable because $\Omega_{1}>0$.

Notice that, for $\delta>\epsilon$ or $\delta<\epsilon$, if $\gamma=\bar{\gamma}$ and $\alpha>\bar{\alpha}$ then $\Omega_{2}=0$. Therefore $\bar{\alpha}_{1}=\Omega_{1}$ and $\bar{\alpha}_{2}=0$. Consequently, the steady-state is unstable because $\Omega_{1}>0$.

\section{F Proposition 8 proof}

Let us rewrite the system 33 as $\dot{M}(t)=J M(t)+B$, where $M$ and $B$ are the corresponding matrices. We define as well

$$
D \equiv\left[\begin{array}{cc}
\bar{\alpha}_{1} & 0 \\
0 & \bar{\alpha}_{2}
\end{array}\right], \quad V \equiv\left[\begin{array}{ll}
v_{11} & v_{12} \\
v_{21} & v_{22}
\end{array}\right]
$$

where $\left(v_{11}, v_{21}\right)$ and $\left(v_{12}, v_{22}\right)$ are, respectively, the eigenvectors of the eigenvalues $\bar{\alpha}_{1}$ and $\bar{\alpha}_{2}$. Since $\bar{\alpha}_{1} \neq \bar{\alpha}_{2}$ the matrix $J$ has two distinct eigenvalues and, therefore, it is diagonalizable. Under this situation the eigenvectors are linearly independent, then $\operatorname{det}(V) \neq 0$ and

$$
V^{-1}=\frac{1}{\operatorname{det}(V)}\left[\begin{array}{cc}
v_{22} & -v_{12} \\
-v_{21} & v_{11}
\end{array}\right]
$$

Our system (33) can be easily solved by means of the change of variable $Z(t) \equiv V^{-1} M(t)$. Since $V^{-1} J V=D, \dot{Z}(t)=D Z(t)+V^{-1} B$. The transformed system involves two independent linear differential equations because $D$ is a diagonal matrix. Solving each equation, and undoing the change of variable as $M(t)=V Z(t)$, yields

$$
\left[\begin{array}{c}
\dot{\tilde{e}}(t) \\
\dot{\tilde{c}}(t)
\end{array}\right]=\left[\begin{array}{l}
v_{11} \psi_{1} \exp \left\{\bar{\alpha}_{1}\right\}+v_{12} \psi_{2} \exp \left\{\bar{\alpha}_{2}\right\}+\tilde{e}^{*} \\
v_{21} \psi_{1} \exp \left\{\bar{\alpha}_{1}\right\}+v_{22} \psi_{2} \exp \left\{\bar{\alpha}_{2}\right\}+\tilde{c}^{*}
\end{array}\right] .
$$

We know that $\bar{\alpha}_{1}>0$ and $\bar{\alpha}_{2}<0$. It is clear from A.21 that $\psi_{1}=0$ in order to satisfy feasibility and TC. The other constant is determined since $e(0)$ is given: $\psi_{2}=$ $v_{12}^{-1}\left[\tilde{e}(0)-\tilde{e}^{*}\right]$. We then obtain $(36)$ and $(37)$. Computing the corresponding eigenvectors of $\bar{\alpha}_{2}$, it is easy to verify that $v_{22} / v_{12}=-(1-\varphi)(\epsilon+\rho) / \bar{\alpha}_{2} \theta>0$. Finally, defining $\bar{\beta} \equiv-\bar{\alpha}_{2}$ and rearranging terms in $(36)$, we can state that

$$
\tilde{e}(t)=(1-\exp \{-\bar{\beta} t\}) \tilde{e}^{*}+\tilde{e}(0) \exp \{-\bar{\beta} t\}
$$


Hence, $\bar{\beta}$ is the speed of convergence of the economy. Notice that, since $y(t)=A e(t)^{\alpha} k(t)^{\gamma}$ and $k(t)=\frac{1}{\sigma} \frac{\gamma}{\alpha} e(t)$, we get from A.22 a similar expression for the income per capita of the economy: $\tilde{y}(t)=(1-\exp \{-\bar{\beta} t\}) \tilde{y}^{*}+\tilde{y}(0) \exp \{-\bar{\beta} t\}$. As usual we obtain $\bar{t}$ by equating $\exp \{-\bar{\beta} \bar{t}\}$ to $1 / 2$.

\section{G Proposition 10 proof}

Without lost of generality we will consider the case $k(0)<h(e(0))$. The proof can be easily adapted for the situation where $k(0)>h(e(0))$. Let us rewrite the social optimum problem as

$$
\max _{\{i, m\}} \int_{0}^{\infty} u(f(e(t), k(t))-i(t)-m(t)) \exp (-(\rho-n) t) d t
$$

subject to

$$
\left\{\begin{array}{l}
\dot{k}(t)=i(t)-(\delta+n) k(t), \\
\dot{e}(t)=\sigma m(t)-(\epsilon+n) e(t)-\vartheta f(e(t), k(t)) .
\end{array}\right.
$$

The idea of the proof is to conjecture that the economy will set $i(t)>0$ for all $t \geq 0$, however $m(t)=0$ for $0 \leq t \leq T<\infty$, and $m(t)>0$ for $t>T$. We should then prove that the conjecture is a solution of the social optimum problem.

Taking into account the positivity constraints for $i(t)$ and $m(t)$, the Hamiltonian of the problem is

$$
\begin{aligned}
& H\left(i, m, k, e, \mu, \lambda, \chi_{k}, \chi_{e}\right)=u(f(e(t), k(t))-i(t)-m(t))+\lambda(t)[i(t)-(\delta+n) k(t)] \\
& +\mu(t)[\sigma m(t)-\vartheta f(e(t), k(t))-(\epsilon+n) e(t)]+\chi_{k}(t) i(t)+\chi_{e} m(t)
\end{aligned}
$$

where $\chi_{e}(t)$ and $\chi_{k}(t)$ are the auxiliary multipliers associated to the positivity constraints. The FOC of the problem are $\partial H / \partial k(t)=(\rho-n) \lambda(t)-\dot{\lambda}(t), \partial H / \partial e(t)=(\rho-n) \mu(t)-\dot{\mu}(t)$, $\partial H / \partial i(t)=0, \partial H / \partial m(t)=0, \chi_{k}(t) i(t)=0, \chi_{e}(t) m(t)=0, \chi_{k}(t) \geq 0$, and $\chi_{e}(t) \geq 0$. Therefore, considering the Hamiltonian A.23,

$$
\begin{gathered}
u^{\prime}(c(t)) f_{k}^{\prime}-(\delta+n) \lambda(t)-\vartheta f_{k}^{\prime} \mu(t)=(\rho-n) \lambda(t)-\dot{\lambda}(t), \\
u^{\prime}(c(t)) f_{e}^{\prime}-(\epsilon+n) \mu(t)-\vartheta f_{e}^{\prime} \mu(t)=(\rho-n) \mu(t)-\dot{\mu}(t), \\
-u^{\prime}(c(t))+\lambda(t)+\chi_{k}(t)=0, \\
-u^{\prime}(c(t))+\sigma \mu(t)+\chi_{e}(t)=0,
\end{gathered}
$$

where $c(t)=f(e(t), k(t))-i(t)-m(t)$. Since in our conjecture $i(t)>0$ then $\chi_{k}(t)=0$. So $\lambda(t)=u^{\prime}(c(t))$ from the FOC. We know moreover that $\lambda(t)=\sigma \mu(t)$ (see Appendix A). Therefore, we also conclude from that

$$
\frac{\sigma-\varphi}{\sigma} f_{k}^{\prime}-\delta-\rho=-\frac{\dot{\lambda}(t)}{\lambda(t)}
$$


Differentiating $\lambda(t)=u^{\prime}(c(t))$ with respect to time, and taking (A.24), we obtain the corresponding Euler condition of our problem:

$$
\frac{\dot{c}(t)}{c(t)}=\frac{1}{\xi(c(t))}\left[\frac{\sigma-\varphi}{\sigma} f_{k}^{\prime}(e(t), k(t))-\delta-\rho\right] .
$$

Hence, for $t \in[0, T]$ the dynamic behaviour of our economy is characterized by the equation A.25), together with laws of motion

$$
\begin{gathered}
\dot{k}(t)=\frac{\sigma-\varphi}{\sigma} f(e(t), k(t))-c(t)-(\delta+n) k(t), \\
\dot{e}(t)=-\varphi f(e(t), k(t))-(\epsilon+n) e(t) .
\end{gathered}
$$

Notice that, for the Cobb-Douglas technology (2), equation (A.27) is a Bernoulli's differential equation, which has a unique solution with a well-known close-form (see, for instance, Sydsæter et al., 2005, p.70). So we can express $e(t)$ as a unique function of $k(t)$, i.e., $e(t)=s(k(t))$. Moreover, since $f(e(t), k(t)) \geq 0$ the environmental quality always decreases for $t \in[0, T]$. This allows us to conclude that $T<\infty$ because otherwise this would contradict the fact that the economy optimally ends up in a positive steady-state $e(t)=e^{*}>0$.

Let us assume that, for $t \geq T, m(t)>0$ such that $k(t)=h(e(t))$. We can therefore describe the behaviour of $e(t)$ as:

$$
e(t)=\eta(k(t)) \equiv \max \left\{h^{-1}(k(t)), s(k(t))\right\}
$$

Consequently, the system that we have to solve comprises the equation A.25 together with the law of motion of physical capital A.26), where $e(t)=\eta(k(t))$. This is a dynamical system of two equations and two unknowns, with the initial condition $k(0)$ and the usual transversality condition (14). As observed in Acemoglu (2009, p.386) and Peters and Simsek (2009, p.167), even if this system is not autonomous it is very similar to the neoclassical growth model. Then, there exists a unique level of $c(0)$ such that the transversality condition will be satisfied, i.e., we have saddle path stability. Therefore, our conjecture satisfies the FOC and the transversality and initial conditions.

\section{References}

Acemoglu D. (2009), Introduction to Modern Economic Growth, Princeton University Press, New Jersey.

Barro R., and X. Sala-i-Martin (2004), Economic Growth, 2nd Edition, The MIT Press, Cambridge, Massachusetts. 
Beharry-Borg N. and R. Scarpa (2010), "Valuing quality changes in Caribbean coastal waters for heterogeneous beach visitors", Ecological Economics, 69, 1124-1139.

Bosi S. and D. Desmarchelier (2017), "Are the Laffer curve and the green paradox mutually exclusive?", Journal of Public Economic Theory, 19, 937-956.

Briguglio L. (1995), "Small Island Developing States and Their Economic Vulnerabilities", World Development, 23(9), 1615-1632.

Brau R. (2008), "Demand-driven sustainable tourism? A choice modelling analysis", Tourism Economics, 14(4), 691-708.

Brock W. and S. Taylor (2010), "The Green Solow model", Journal of Economic Growth, 15(2), 127-153.

Burak S., E. Dogan and C. Gazioglu (2004), "Impact of urbanization and tourism on coastal environment", Ocean \& Coastal Management, 47, 515-527.

Cambers G. (2009), "Caribbean beach changes and climate change adaptation", Aquatic Ecosystem Health \& Management, 12(2), 168-176.

Caserta S. and A. Russo (2002), "More Means Worse: Asymmetric Information, Spatial Displacement and Sustainable Heritage Tourism", Journal of Cultural Economics, 26, 245-260.

Christ C., O. Hillel, S. Matus and J. Sweeting (2003), Tourism and biodiversity, United Nations Environmental Programme (UNEP) and Conservation International, Washington, DC.

Copeland B. and S. Taylor (2001), "International Trade and the Environment: A Framework for Analysis", NBER Working Papers, 8540.

Cowen T. and A. Tabarrok (1995), "Good grapes and bad lobsters: Applying the Alchian and Allen Theorem", Economic Inquiry, 33, 253-256.

Dasgupta P. and G. Heal (1974), "The optimal depletion of exhaustible resources", Review of Economic Studies, special number, 41, 3-28.

Fleischer A. and J. Rivlin (2008), "More or Better? Quantity and Quality Issues in Tourism Consumption", Journal of Travel Research, 47(3), 285-294.

Font A. (2000), "Mass tourism and the demand for protected natural areas: a travel cost approach", Journal of Environmental Economics and Management, 39, 97-116.

Geldrop J. and Withagen C. (1999), "General equilibrium and resource economics", Economic Theory, 14, 691-704. 
Grossman G. and A. Krueger (1995), "Pollution Growth and the environment", Quaterly Journal of Economics, 110, 353-377.

Gopalakrishnan S., M. Smith, J. Slott and A. Murray (2011), "The value of disappearing beaches: A hedonic pricing model with endogenous beach width" , Journal of Environmental Economics and Management, 34, 1187-1201.

Gómez C., J. Lozano and J. Rey-Maquieira (2008), "Environmental policy and long-term welfare in a tourism economy", Spanish Economics Review, 10, 41-62.

Gössling S., C. Hansson, O. Hörstmeier and S. Saggel (2002), "Ecological footprint analysis as a tool to assess tourism sustainability", Ecological Economics, 43, 199-211.

Huybers T. and J. Bennett (2003), "Environmental management and the competitiveness of nature-based tourism destinations", Environmental and Resource Economics, 24, 213-233.

Kijima M., K. Nishide and A. Ohyama (2010), "Economic models for the environmental Kuznets curve: A survey", Journal of Economic Dynamics and Control, 34, 1187-1201.

Kocasoy G. (1995), "Effects of Tourism Population Pressure on Pollution of Coastal Seas" , Environmental Management, 19(1), 75-79.

Kort P., A. Greiner, G. Feichtinger, J. Haunschmied, R. Hartl and A. Novak (2002), "Environmental effects of tourism industry investments", Optimal Control Applications and Methods, 23, 1-19.

Landry C. and A. Keeler (2003), "An economic evaluation of beach erosion management alternatives", Marine Resource Economics, 18, 105-127.

Le Kama A. and Schubert (2007), "A note on the consequences of an endogenous discounting depending on the environmental quality", Macroeconomic Dynamics, 11(2), 272-289.

Lozano J., C. Gomez and J. Rey-Maquieira (2008), "The TALC hypothesis and economic growth theory", Tourism Economics, 14, 727-749.

Mariani F., A. Pérez-Barahona and N. Raffin (2010), "Life expectancy and the environment", Journal of Economic Dynamics and Control, 34 (4), 798-815.

Marsiglio (2015), "Economic growth and environment: tourism as a trigger for green growth", Tourism Economics, 21, 183-204.

Marsiglio (2017), "On the Carrying Capacity and the Optimal Number of Visitors in Tourism Destinations", Tourism Economics, 23, 632-646. 
May V. (1995), "Environmental implications of the 1992 Winter Olympic Games", Tourism Management, 16, 269-275.

McConnell K. (1977), "Congestion and Willingness to Pay: A Study of Beach Use", Land Economics, 53(2), 185-195.

McConnell K. and V. Duff (1976), "Estimating net benefits of outdoor recreation under conditions of excess demand", Journal of Environmental Economics and Management, $2,224-230$.

McElroy J. and K. Albuquerque (1998), "Tourism penetration index in Small Caribbean Islands", Annals of Tourism Research, 25(1), 145-168.

Munk W. and M. Traylor (1947), "Refraction of Ocean Waves: A Process Linking Underwater Topography to Beach Erosion", The Journal of Geology, 55, 1-26.

Peters M. and A. Simsek (2009), Solutions Manual for Introduction to Modern Economic Growth, Princeton University Press, New Jersey.

Polasky S., C. Costello, and A. Solow (2005), "The economics of biodiversity", in K.-G. Muller and J.R. Vincent, Eds, Handbook of Environmental Economics, Elsevier B.V., Amsterdam, The Netherlands.

Rey-Maquieira J., J. Lozano and C. Gómez (2009), "Quality standards versus taxation in a dynamic environmental model of a tourism economy", Environmental Modelling $\&$ Software, 24, 1483-1490.

Roca E., M. Villares and M. Ortego (2009), "Assessing public perceptions on beach quality according to beach users' profile: A case study in the Costa Brava (Spain)", Tourism Management, 30, 598-607.

Rosendahl K. (1997), "Does Improved Environmental Policy Enhance Economic Growth?", Environmental and Resource Economics, 9(3), 341-364.

Rosen S. (1974), "Hedonic prices and implicit markets: product differentiation in pure competition", Journal of Political Economy, 82, 34-55.

Santana-Jiménez Y. and J. Hernández (2011), "Estimating the effect of overcrowding on tourist attraction: The case of Canary Islands", Tourism Management, 32, 415-425.

Schumacher I. (2015), "The endogenous formation of an environmental culture", European Economic Review, 76, 200-221.

Scott D., M. Simpson and R. Sim (2012), "The vulnerability of Caribbean coastal tourism to scenarios of climate change related sea level rise", Journal of Sustainable Tourism, 20(6), 883-898. 
Seiertad A. and K. Sydsæter, 1987, Optimal Control Theory with Economic Applications, North Holland, Amsterdam.

Silva J., S. Barbosa and M. Costa (2008), "Flag Items as a Tool for Monitoring Solid Wastes from Users on Urban Beaches", Journal of Coastal Research, 24(4), 890-898.

Silva S. and J. Ferreira (2013), "Beach Carrying Capacity: The physical and social analysis at Costa de Caparica, Portugal", Journal of Coastal Research, 65 (special issue), 1039-1044.

Smulders S., Y. Tsur and A. Zemel (2012), "Announcing climate policy: Can a green paradox arise without scarcity?", Journal of Environmental Economics and Management, 64 (3), 364-376.

Stiglitz J. (1974), "Growth with Exhaustible Natural Resources: Efficient and Optimal Growth Paths", Review of Economic Studies, special number, 41, 123-137.

Sydsæter K., A. Strøm, and P. Berck (2005), Economists' Mathematical Manual, SpringerVerlag, Berlin.

Tahvonen O. and S. Salo (2001), "Economic growth and transitions between renewable and nonrenewable energy resources", European Economic Review, 45(8), 1379-1398.

Tisdell C.(2001), Tourism Economics, the Environment and Development, Edward Elgar, Cheltenham.

United Nations World Tourism Organization, UNWTO (2002), The British Ecotourism Market, UNWTO, Madrid.

United Nations World Tourism Organization, UNWTO (2012), Challenges and opportunities for tourism development in small island developing states, UNWTO, Madrid.

Vallés S., J. Gallego Fernández and C. Dellafiore (2011), "Dune Vulnerability in Relation to Tourism Pressure in Central Gulf of Cádiz (SW Spain), a Case study", Journal of Coastal Research, 27(2), 243-251.

van der Velde M., S. Green, M. Vancloostera and B. Clothier (2007), "Sustainable development in small island developing states: Agricultural intensification, economic development, and freshwater resources management on the coral atoll of Tongatapu", Ecological Economics, 61, 456-468.

World Bank (1998), Think Tank Group and World Tourism Organization Examine Role of Tourism in Development, News Release No. 98/1853/S, 25 June 1998, Washington, DC. 
World Travel \& Tourism Council, WTTC (2017a), WTTC Travel \& Tourism Economic Impact 2017, Caribbean, WTTC, London.

World Travel \& Tourism Council, WTTC (2017b), WTTC Travel \& Tourism Economic Impact 2017, World, WTTC, London. 